\title{
Effect of providing free glasses on children's educational outcomes in China: cluster randomized controlled trial
}

\author{
(c) (1) (8) OPEN ACCESS
}

\author{
Xiaochen Ma graduate student ${ }^{12}$, Zhongqiang Zhou graduate student ${ }^{3}$, Hongmei Yi professor ${ }^{4}$, \\ Xiaopeng Pang professor ${ }^{5}$, Yaojiang Shi professor ${ }^{6}$, Qianyun Chen research assistant ${ }^{3}$, Mirjam E \\ Meltzer biostatistician ${ }^{3}$, Saskia le Cessie professor ${ }^{78}$, Mingguang He professor ${ }^{3}$, Scott Rozelle \\ professor $^{9}$, Yizhi Liu professor ${ }^{3}$, Nathan Congdon professor ${ }^{310}$
}

'Department of Agriculture and Resource Economics, University of California, Davis, Davis, CA, USA; ${ }^{2}$ Stanford Center For International Development, Stanford University, Stanford, CA, USA; ${ }^{3}$ Key Laboratory of Ophthalmology and Division of Preventive Ophthalmology, Zhongshan Ophthalmic Center, Sun Yat-sen University, Guangzhou, China; ${ }^{4}$ Center for Chinese Agricultural Policy, Institute of Geographical Sciences and Natural Resources Research, Chinese Academy of Sciences, Beijing, China; ${ }^{5}$ School of Agricultural Economics and Rural Development, Renmin University of China, Beijing, China; ${ }^{6}$ School of Economic Management, Xibei University, Xi'an, China; ${ }^{7}$ Department of Clinical Epidemiology, Leiden University Medical Center, Leiden, Netherlands; ${ }^{8}$ Department of Medical Statistics and Bioinformatics, Leiden University Medical Center, Leiden, Netherlands; ${ }^{9} \mathrm{Freeman}$ Spogli Institute of International Studies, Stanford University, Stanford, CA, USA $;{ }^{10}$ ORBIS International, New York, NY, USA

\begin{abstract}
Objective To assess the effect of provision of free glasses on academic performance in rural Chinese children with myopia

Design Cluster randomized, investigator masked, controlled trial.

Setting 252 primary schools in two prefectures in western China 2012-13.

Participants 3177 of 19934 children in fourth and fifth grades (mean age 10.5 years) with visual acuity $<6 / 12$ in either eye without glasses correctable to $>6 / 12$ with glasses. $3052(96.0 \%)$ completed the study.

Interventions Children were randomized by school ( 84 schools per arm) to one of three interventions at the beginning of the school year: prescription for glasses only (control group), vouchers for free glasses at a local facility, or free glasses provided in class.

Main outcome measures Spectacle wear at endline examination and end of year score on a specially designed mathematics test, adjusted for baseline score and expressed in standard deviations.

Results Among 3177 eligible children, 1036 (32.6\%) were randomized to control, 988 (31.1\%) to vouchers, and $1153(36.3 \%)$ to free glasses in class. All eligible children would benefit from glasses, but only $15 \%$ wore them at baseline. At closeout glasses wear was $41 \%$ (observed) and $68 \%$ (self reported) in the free glasses group, and $26 \%$ (observed) and $37 \%$ (self reported) in the controls. Effect on test score was 0.11
\end{abstract}

SD $(95 \%$ confidence interval 0.01 to 0.21$)$ when the free glasses group was compared with the control group. The adjusted effect of providing free glasses $(0.10,0.002$ to 0.19$)$ was greater than parental education $(0.03,-0.04$ to 0.09$)$ or family wealth $(0.01,-0.06$ to 0.08$)$. This difference between groups was significant, but was smaller than the prespecified 0.20 SD difference that the study was powered to detect.

Conclusions The provision of free glasses to Chinese children with myopia improves children's performance on mathematics testing to a statistically significant degree, despite imperfect compliance, although the observed difference between groups was smaller than the study was originally designed to detect. Myopia is common and rarely corrected in this setting.

Trial Registration Current Controlled Trials ISRCTN03252665.

\section{Introduction}

Poor vision is the most common impairment affecting school aged children in the developing world, comprising $48 \%$ of all disability among children aged 5 to 9 years in the India census of 2001. ${ }^{1}$ The leading and most easily remedied cause of visual impairment (visual acuity <6/18) among children is refractive error, affecting 12.8 million children aged between 5 and 15 years, half of whom live in China. ${ }^{2}$ Spectacles provide a safe and inexpensive treatment. Several studies report that children 
with uncorrected refractive errors have lower scores on a variety of motor and cognitive tests, ${ }^{3-6}$ and that improvements in reading may occur when vision problems are corrected. ${ }^{67}$

However, the relation between academic achievement and refractive error may be complex. Hyperopia (far sightedness), causing difficulty in seeing close objects, is more likely to cause reading problems and is the focus of many studies of refractive error and school performance. ${ }^{5}$ Myopia (near sightedness) causes difficulty in seeing distant objects and is more common in school aged children, particularly in Asia. ${ }^{8-10}$ Myopia is responsible for more than $90 \%$ of poor vision among children in China.${ }^{8}$ Prevalence of myopia may exceed $60 \%$ in rural areas ${ }^{911}$ and $80 \%$ in ethnically Chinese urban populations, ${ }^{12}$ and two thirds or more of rural Chinese children with myopia are without accurate correction. ${ }^{13}$ The high prevalence of myopia among Chinese children seems to be due in part to high levels of near work related to school and limited time spent outdoors. ${ }^{14}$ Barriers to accessing refractive care include cost and poor quality of available glasses and lack of knowledge about myopia and the benefits of its correction. ${ }^{15}$

It also seems that higher scholastic attainment is associated with risk of myopia. ${ }^{14}$ Thus, the directionality of cause and effect between myopia and school performance is unclear. Myopia will not cause difficulties with near reading except in extreme cases, but it could prevent material on a blackboard from being clearly seen. A recent review of school vision screening practices found no randomized trials examining the impact of correcting myopia on school performance. ${ }^{16}$ Such trials are needed owing to the scope of the myopia problem; the effect of myopia on classroom learning is not well understood, and the randomized controlled study design can clarify any causal association between the correction of myopia and school outcomes.

We carried out a cluster randomized, factorial design, controlled trial in rural western China to evaluate the effect of teaching about the value of glasses and providing free spectacles on rates of glasses wear and school performance. Cluster randomization was used because of the difficulty of assigning children to different interventions at one school. We hypothesized that education promoting the wearing of glasses aimed at school children with correctable refractive error, their teachers, and parents, and providing such children with free spectacles, would increase children's glasses wear (intermediary hypothesis) and improve their academic performance (main hypothesis).

\section{Methods}

\section{Setting}

The study was carried out in two neighboring areas of western China. Tianshui prefecture is a deprived area $^{17}$ in one of China's lowest resource provinces, ${ }^{18}$ Gansu. Yulin prefecture is a relatively affluent area, ${ }^{19}$ in middle income ${ }^{18}$ Shaanxi province.

\section{Sampling and eligibility criteria}

We obtained a list of all 435 primary schools in the two prefectures from local education bureaus. For logistical reasons we excluded those with fewer than 50 or more than 150 students in the fourth and fifth grade combined (19\% of sample frame). This is because screening at the larger schools could not be reliably completed in a day, which would have interfered with the screening schedule, whereas smaller schools would be expected to have fewer than 10 children requiring glasses, below our power requirements. We randomly selected one school from each township in the sample, and within each school we randomly selected one class in each of the fourth and fifth grades (likely age range 9-12 years). Children at the 252 selected schools were eligible if they had an uncorrected (without glasses) visual acuity of $\leq 6 / 12$ in either eye and their refractive error met the cut-offs shown to be associated with significantly greater improvement in visual acuity when corrected ${ }^{20}$ (myopia $\leq-0.75$ diopters $(\mathrm{D})$, hyperopia $\geq 2.00 \mathrm{D}$, or astigmatism (non-spherical refractive error) $\geq 1.00 \mathrm{D}$ ); and visual acuity could be improved to $>6 / 12$ in both eyes with glasses.

\section{Questionnaires}

At baseline (September 2012, beginning of the school year), enumerators administered questionnaires to children on age, sex, glasses wear, awareness of refractive status, belief that wearing glasses harms vision (a common misapprehension in China $^{1321}$ ), boarding at school, and parental migration and education. A parental questionnaire asked about ownership of 13 selected items as an index of family wealth. Mathematics teachers were asked to state whether the blackboard (potentially not clearly seen by myopic children) was used for all, most, about half, little, or none of teaching.

\section{Visual acuity assessment}

Children underwent baseline visual acuity screening at school by a nurse and trained assistant. Visual acuity was tested separately for each eye without refraction at $4 \mathrm{~m}$ using early treatment diabetic retinopathy study charts ${ }^{22}$ (Precision Vision, La Salle, IL) in a well lighted, indoor area. These charts are preferred in vision research because of regular progression in letter size and uniform spacing between lines. The measured visual acuity is based on the precise number of letters read and thus is more accurate and repeatable than with Snellen charts employed in routine clinical practice.

If children correctly identified the orientation of at least four of five optotypes on the $6 / 60$ line, they were examined on the $6 / 30$ line, then the $6 / 15$ line, and then line by line to $6 / 3$. We defined visual acuity for an eye as the lowest line on which four of five optotypes were read correctly. If the top line could not be read at $4 \mathrm{~m}$, the participant was tested at $1 \mathrm{~m}$ and the measured visual acuity was divided by 4 .

\section{Refraction (measurement of glasses power)}

Children with uncorrected visual acuity $\leq 6 / 12$ in either eye underwent cycloplegia (paralysis of accommodation (focusing at near) accompanied by pupil dilation) with up to three drops of cyclopentolate $1 \%$ in each eye after anesthesia with topical proparacaine hydrochloride $0.5 \%$, to prevent inaccurate refraction. Children then underwent automated refraction (Topcon KR 8900, Tokyo, Japan) with subjective refinement by a local refractionist, previously trained by experienced optometrists from Zhongshan Ophthalmic Center.

\section{Randomization and interventions}

This was a cluster randomized, factorial design, controlled trial, with schools as the clusters. In October 2012, after the baseline survey and vision screening but before refraction, eligible children were randomized by school to receive one of three interventions:

- Free spectacles, based on the child's measured refractive power and dispensed at school by the study optometrist. A letter with information about the free glasses program and including the child's prescription was sent to parents. Eighty four schools were allocated to the free glasses group. 
- Vouchers bearing the child's name, school, and glasses prescription, exchangeable for free glasses at the local county hospital, at a median distance from children's townships of $30 \mathrm{~km}$ (range 1-105 km). Parents were responsible for paying the transportation costs. Vouchers could not be exchanged or sold, and students were required to produce school identification to redeem them. Children whose families did not redeem their vouchers received free glasses at study closeout, though this was not previously announced. Eighty four schools were allocated to the voucher group.

- A glasses prescription and letter to the parents informing them of the refractive status of their child, with free glasses provided only at closeout, although this was not previously announced. Eighty four schools were allocated to the control group.

Within each group, schools were randomized in October 2012 to receive an educational intervention promoting spectacle wear (education group) or no education. There were six groups of 42 schools in this $3 \times 2$ factorial design. Schools were stratified by three variables, information on which was collected during the baseline survey and screening: county; the total number of students in grades 4 and 5; and the number of students failing vision screening in grades 4 and 5. Within each stratum a school was randomly assigned to one of the six treatment arms. Stratification and random assignment were carried out at a central location (Stanford University, Stanford, CA) using R software (R Foundation for Statistical Computing, Vienna, Austria).

Participants (students, parents, and teachers) and enumerators were not informed of either the overall design of the study or the explicit treatment arm assignment. Participants were told only that this was a study of vision care among rural, school aged children. Only one school was selected in each township, minimizing the possibility of cross arm communication and contamination.

\section{Educational intervention}

Children at education group schools watched a 10 minute documentary style video and were given a booklet of cartoons, followed by a classroom discussion led by study staff. All children in the selected classes, regardless of vision status, participated. These materials showed children experiencing the benefits of glasses and teachers explaining that glasses do not harm vision. Teachers and parents viewed a presentation at school on the safety and benefits of glasses, accompanied by a brochure with similar information, and posters with similar content were hung in classrooms. All materials delivered to children, teachers, and parents were designed to convey the same set of messages: that myopia is common in China, that glasses provide the safest and most effective treatment of myopia for children, and that wearing glasses does not harm children's eyes. Study staff returned in December 2012 to reinforce these messages, which were based on previous research in rural China. ${ }^{1321} 23$

\section{Outcome assessment: mathematics test and glasses wear}

Separate mathematics tests appropriate for children in the fourth and fifth grades were administered on printed paper by research staff at baseline and closeout (May-June 2013: end of the school year). Local educators assisted with the selection of questions from items developed for the Trends in International Mathematics and Science Study (http://timss.bc.edu/home/pdf/
TP_About.pdf). The examination was timed (25 minutes) and proctored by two study enumerators at each school. Mathematics was chosen for testing to reduce the effect of home learning on performance and to better focus on classroom learning. At closeout, spectacle wear was assessed through unannounced direct examinations. Children also described their own spectacle wear as "always," "only for studying," or "usually not worn." Study staff were masked to group assignment.

\section{Sample size}

Using Optimal Design software, ${ }^{24}$ we determined that a sample size of 252 schools with a minimum of 10 students for each school conferred $90 \%$ power, with an $\alpha$ of 0.05 , intraclass correlation of 0.15 , and explained variation by covariates $\left(\mathrm{R}^{2}\right)$ of 0.50 , to detect a difference of 0.20 standard deviations in endline math score between intervention arms and the control group.

\section{Statistical analysis}

We standardized baseline and endline math score for each grade separately to give a mean of 0 and SD of 1 among control group children at baseline. Baseline wear of glasses was defined as having glasses at school. We calculated family wealth by summing the value, as reported in the China Rural Household Survey Yearbook (Department of Rural Surveys, National Bureau of Statistics of China, 2013), of items on the list of 13 owned by the family. Refractive power was defined throughout as the spherical equivalent - that is, the spherical power plus half the cylindrical power.

All analyses were performed using Stata 12.0 (StataCorp, College Station, TX), calculating robust standard errors to adjust for clustering by school. ${ }^{25}$ We compared randomization groups by intention to treat using multiple linear regression, with endline math score as the main outcome for the main hypothesis and intervention arms and baseline math score as covariates. Other baseline variables were investigated as predictors for math score, with the final model including intervention arms and variables associated with baseline math score at $\mathrm{P} \leq 0.20$. For the intermediary hypothesis on glasses wear, the primary outcome was observed wear at closeout and the secondary outcome was self reported wear ("only for studying" or "always," compared with "mostly not worn"). For intention to treat analyses with wear as outcome, we used generalized linear models with Poisson regression to estimate the relative risk for intervention arms, adjusting for baseline wear and other covariates. We used one way analysis of variance to estimate the intraclass correlation coefficient as a measure of clustering of endline math score and glasses wear within school.

\section{Missing data}

To satisfy the requirements of intention to treat analysis that all enrolled children should be included in analyses, we carried out imputation of missing data: we imputed age $(n=3)$ using the grade specific mean age. Missing data for spherical equivalent refractive error $(n=2)$ were replaced by the median spherical equivalent for the associated level of visual acuity, and missing data for boarding at school at baseline (yes/no) $(n=3)$ were replaced by the data for boarding at school at endline.

We used multiple imputation in Stata as described previously ${ }^{26}$ to impute several data at baseline: math score $(n=1)$, outmigration of father $(n=24)$, outmigration of mother $(n=41)$, family wealth $(n=145)$, education level of father $(n=14)$, education of mother $(n=23)$, and awareness of being myopic $(n=20)$. Data imputed at endline were math score $(n=125)$, self 
reported wear of glasses $(\mathrm{n}=123)$, and observed wear of glasses $(\mathrm{n}=123)$. We used linear regression for continuous variables, logistic regression for binary variables, and ordinal logistic regression for ordinal variables. For each variable we used different models, selecting the independent variables based on predictive value and availability of data. The multiple imputation approach created 20 copies of the data in which missing values were imputed by chained equations. ${ }^{26}$ Final results were obtained by averaging these 20 datasets using Rubin's rules, which ensured that the standard errors for all regression coefficients took into account uncertainty in the imputations as well as uncertainty in the estimation. ${ }^{26}$

\section{Results}

Among 19934 children screened at 252 selected schools, 4839 $(24.3 \%)$ failed visual acuity screening and were randomized (figure $\Downarrow$ ). A total of $3177(65.4 \%$ ) children in 251 schools were eligible for allocation (visual acuity improving with refraction); one school was excluded because there were no children at that school that met the inclusion criteria. The voucher group had lower baseline math scores than the control and free glasses groups. Tables $1 \Downarrow$ and $2 \Downarrow$ show the distribution of various factors between groups at baseline. The supplementary figure shows the distribution of refractive power among children allocated in the trial.

In the 251 schools, intention to treat analyses were performed on all 1036 children in the control group, 988 in the voucher group, and 1153 in the free glasses group. Among 123 missing children, $26(21 \%)$ were at home the day of follow-up, 90 (73\%) had transferred to other schools, and $7(6 \%)$ had withdrawn from school. Children with follow-up did not differ in any baseline variables from those without follow-up (data not shown).

All eligible children would benefit from glasses, but only $15 \%$ wore them at baseline. At closeout the wear of glasses was $41 \%$ (observed) and 68\% (self reported) in the free glasses group and $26 \%$ (observed) and 37\% (self reported) among controls.

Table $3 \Downarrow$ gives the baseline, endline, and change in the mathematics score by study group. Intention to treat analyses showed a significant difference in endline score adjusted for baseline score of $0.11 \mathrm{SD}$ (95\% confidence interval 0.01 to 0.21 , $\mathrm{P}=0.03)$ for the free glasses group and $0.04(-0.05$ to 0.14 , $\mathrm{P}=0.35)$ for the voucher group compared with controls. The unadjusted intraclass correlation coefficient for endline math score was 0.12; adjusted for baseline scores it was 0.07 .

In intention to treat models adjusting for baseline math score, allocation to the free glasses group, younger age, residence in Shaanxi, and parental education were significantly associated with higher endline math score. Allocation to the voucher group, sex, refractive error, family wealth, boarding at school, and parental migration for work were unassociated with endline score (table $4 \Downarrow$ ). In the full multiple model, baseline score, allocation to the free glasses group $(0.10 \mathrm{SD}, 95 \%$ confidence interval 0.002 to $0.19, \mathrm{P}=0.04$ ), younger age, and residence in Shaanxi remained associated with endline score (table 4). This difference between groups in testing was statistically significant but smaller than the 0.20 SD prespecified difference that the study was powered to detect.

In a post hoc exploratory analysis stratifying by classroom black board use, effect size was larger for children in classrooms where blackboards were utilized more regularly: among 156 (4.9\%) children in classrooms where the blackboard was used for all teaching, the free glasses group scored $0.45 \mathrm{SD}(0.11$ to $0.80, \mathrm{P}=0.01)$ higher than controls, among $982(31.0 \%)$ children using the blackboard for most or all teaching, the free glasses group scored $0.23 \mathrm{SD}(0.04$ to $0.42, \mathrm{P}=0.02)$ higher than controls, among 2181 (68.8\%) children using the blackboard half or more of the time the difference was $0.14 \mathrm{SD}(0.03$ to $0.26, \mathrm{P}=0.01)$, and among $988(31.2 \%)$ children receiving little or no blackboard teaching, the difference was $-0.01(-0.17$ to $0.14, \mathrm{P}=0.87$ ).

Table $5 \Downarrow$ shows baseline and endline observed and self reported glasses wear among children in the trial. The provision of both free glasses and vouchers increased the wearing of glasses compared with controls, as measured by both observed and self reported wear. The educational intervention increased self reported but not observed wear (table 5). No interaction was found between the glasses and education interventions on either outcome. Results of analyses using multiple imputation were very similar to results of analyses using only participants with complete data (data not shown).

\section{Discussion}

In this trial, a statistically significant impact on math test scores was found by intention to treat analysis among Chinese children randomized to receive free glasses, although this difference between groups was smaller than the prespecified difference that the study was powered to detect. This effect size was also smaller than the difference between the voucher and free glasses groups at baseline $(0.14 \mathrm{SD})$. The observed effect size of 0.11 $\mathrm{SD}$ is the equivalent of approximately half a semester of additional learning, based on a previous report ${ }^{27}$ that average annual gains for students between the fourth and fifth grades was $0.4 \mathrm{SD}$. Allocation to the free glasses group had a greater effect on math test scores than either parental education or family wealth and was similar to the effect of residence in middle income Shaanxi compared with much lower income Gansu. The fact that effect size increased with increasing classroom blackboard use (a post hoc analysis) adds biological plausibility, as reliance on blackboards created greater demands on distance vision for myopic children.

The voucher intervention was explored because vouchers are logistically easier to implement than school based distribution of glasses. We speculate that the non-significant effect on test scores in the voucher group was due to the combined influence of slightly lower rates of glasses wear in the voucher compared with free glasses group, and slightly shorter opportunity for glasses wear to affect learning in the voucher group owing to the logistics of securing spectacles (although $85 \%$ of families did redeem their vouchers in the first three weeks after receiving them).

We observed a statistically significant impact of providing glasses on academic performance even though compliance with wear was imperfect. New approaches to encourage the use of glasses may increase academic benefits of providing glasses. In a separate trial we are studying teacher incentives to promote the use of glasses in the classroom.

\section{Strengths and limitations of this study}

Strengths of this study include population based sampling, a randomized controlled design, and high participation and follow-up rates, all of which increase confidence in the findings. However, all schools were in rural northwest China, which limits external validity with reference to other populations. Other weaknesses include that is was not practical to mask the participants. Compliance with glasses was imperfect, and we did not assess the day to day use of glasses, making it difficult 
to accurately gauge effect size among children with the most regular wear.

Two of our inclusion criteria, enrolling children already wearing glasses $(n=463,15.0 \%)$ and those with poor vision in only one eye $(n=402,12.7 \%)$, might have decreased the effect size. We included (and re-refracted) children who already wore glasses in view of reports of the poor quality of glasses in rural China. ${ }^{28}$ Excluding these groups did not change our results (data not shown).

\section{Comparison with other studies}

We searched the PubMed database in January 2014 for articles in any language published since 1970, using the terms "correction" cross indexed with "refractive error" and "myopia"; "school," "educational," and "academic"; and "impact," "outcomes," and "performance." Some uncontrolled studies have reported lower achievement scores among children with uncorrected, mostly hyperopic, refractive error, ${ }^{3-6}$ though a Singapore study of predominantly myopic children found no association between distance visual acuity and later academic performance. ${ }^{29} \mathrm{We}$ found no randomized trials dealing with the impact of correcting refractive error on school performance, nor did a recent systematic review. ${ }^{16}$

A recent unpublished review (Improving learning in primary schools of developing countries: a meta-analysis of randomized experiments http://academics.wellesley.edu/Economics/mcewan/ PDF/meta.pdf, accessed 17 January 2014) of randomized trials with educational outcomes in primary schools in the developing world listed 60 health related trials, including 22 of deworming, with a mean effect size of $0.013 \mathrm{SD}$, and 38 of nutritional or micronutrient supplementation, with a mean effect size of 0.035 $\mathrm{SD}$. It would seem that the effect size on education outcomes with the provision of glasses in this study compares favorably with that of other health related interventions.

\section{Conclusions and policy implications}

Myopia is common among rural Chinese children and increases with age. ${ }^{14}$ Even in these relatively young children, 1 in 6 (15.9\%) had poor vision due to refractive error. Only $15 \%$ of these children who needed glasses had them, and the number using glasses could be nearly doubled by providing them free compared with giving a prescription (table 4). Data from our baseline survey showed that among children who owned glasses the median price paid was approximately $\$ 60$. This represents nearly half the monthly income for rural families in China, $\$ 130$ in $2012 .{ }^{30}$ While cost is a major barrier for families in obtaining glasses, high quality spectacles can be purchased in bulk for less than $\$ 5$, which would make them affordable for government programs. In fact, as a result of this project, pilot programs have now started in Shaanxi and Gansu Provinces to provide free glasses to children, with the possibility of expansion if successful.

China's rural health insurance system (the New Cooperative Medical Scheme) covered $96 \%$ of rural dwellers by $2011,{ }^{31}$ and has begun experimenting in limited areas with providing free glasses. Results of our trial suggest this inexpensive intervention can increase academic outcomes to a statistically significant extent. The amount of the effect on testing outcomes was less than the prespecified size our study was designed to detect, but is greater in classrooms where blackboards are used extensively.

As an important reason for non-wear of glasses in China is the widespread perception that wearing glasses can harm children's vision, ${ }^{132}$ we will present data in a separate paper on the effect of providing glasses on one year change in uncorrected visual acuity.

Contributors: XCM and SR designed the study, collected and analyzed the data, and revised the manuscript. ZQZ, HMY, YJS, and QYC collected the data and revised the manuscript. XPP, MGH, and YL designed the study and revised the manuscript. MEM and SIC analyzed the data and revised the manuscript. NC designed the study, collected and analyzed the data, and wrote the manuscript. He is guarantor. All of the authors had full access to all of the data in the study and take responsibility for the integrity of the data and the accuracy of the data analysis.

Funding: This study was funded by OneSight (Mason, $\mathrm{OH}$ ), Luxottica-China (Shanghai), Essilor-China(Shanghai), CLSA (Asia Pacific Markets; Hong Kong), Charity Aid Foundation (Sydney), and an anonymous donor (Hong Kong). NC is supported by a Thousand Man Plan grant from the Chinese government. The study sponsors had no role in study design; the collection, analysis, and interpretation of data; the writing of the report; or the decision to submit the paper for publication.

Competing interests: All authors have completed the ICMJE uniform disclosure form at www.icmje.org/coi_disclosure.pdf and declare: the free glasses used in this study were supplied by OneSight,

Luxottica-China, and Essilor-China, producers of frames and lenses in China who also provided financial support for the study; the authors have no other financial relationships with any organisations that might have an interest in the submitted work in the previous three years; and no other relationships or activities that could appear to have influenced the submitted work.

Ethical approval: This study was approved by the institutional review boards at Stanford University (Palo Alto, USA) and the Zhongshan Ophthalmic Center (Guangzhou, China). Permission was received from local boards of education in each region and the principals of all schools. The presented data are anonymized and risk of identification is low. The principles of the Declaration of Helsinki were followed throughout. Data sharing: The full dataset and statistical code are available at www. stanford.edu/REAP with open access.

Transparency: NC (the manuscript's guarantor) affirms that the manuscript is an honest, accurate, and transparent account of the study being reported; that no important aspects of the study have been omitted; and that any discrepancies from the study as planned (and, if relevant, registered) have been explained.

1 Dimension of Disability in India, chapter 4, table 4.3 (b). 2013. http://mospi.nic.in/Mospi New/upload/disablity_india_statistical_data_11mar2011/Chapter\%204-Dimension Disability.pdf.

2 Resnikoff S, Pascolini D, Mariotti SP, Pokharel GP. Global magnitude of visual impairment caused by uncorrected refractive errors in 2004. Bull World Health Organ 2008;86:63-70.

3 Krumholtz I. Results from a pediatric vision screening and its ability to predict academic performance. Optometry 2000;71:426-30.

4 Atkinson J, Anker S, Nardini M, Braddick O, Hughes C, Rae S, Wattam-Bell J, Atkinson S. Infant vision screening predicts failure on motor and cognitive tests up to school age. Strabismus 2002;10:187-98.

5 Williams WR, Latif AH, Hannington L, Watkins DR. Hyperopia and educational attainment in a primary school cohort. Arch Dis Childhood 2005;90:150-3.

6 Roch-Levecq AC, Brody BL, Thomas RG, Brown SI. Ametropia, preschoolers' cognitive abilities, and effects of spectacle correction. Arch Ophthalmol 2008;126:252-8.

7 Johnson R, Nottingham D, Stratton R, Zaba J. The vision screening of academically and behaviorally at-risk pupils. J Behavioral Optom 1996:7:39-42.

$8 \mathrm{He} \mathrm{M}$, Zeng J, Liu Y, Xu J, Pokharel GP, Ellwein LB. Refractive error and visual impairment in urban children in southern China. Invest Ophthalmol Vis Sci 2004;45:793-9.

9 He M, Huang W, Zheng Y, Huang L, Ellwein LB. Refractive error and visual impairment in school children in rural southern China. Ophthalmology 2007;114:374-82.

10 Murthy GV, Gupta SK, Ellwein LB, Muñoz SR, Pokharel GP, Sanga L, et al. Refractive error in children in an urban population in New Delhi. Invest Ophthalmol Vis Sci 2002;43:623-31.

11 Congdon NG, Wang Y, Song Y, Choi K, Zhang M, Zhou Z, et al. Visual disability, visual function and myopia among rural Chinese secondary school children: the Xichang Pediatric Refractive Error Study (X-PRES) Report \#1. Invest Ophthalmol Vis Sci 2008;49:2888-94.

12 Wu HM, Seet B, Yap EP, Saw SM, Lim TH, Chia KS. Does education explain ethnic differences in myopia prevalence? A population-based study of young adult males in Singapore. Optom Vis Sci 2001;78:234-9. 


\section{What is already known on this topic}

Studies have shown that reading can be improved in children after refractive correction of hyperopia but the impact of myopia (near sightedness) on classroom learning is not well understood

Higher scholastic achievement may increase the risk of myopia, so the direction of cause and effect between myopia and school attainment is not clear

No randomized trials have assessed the impact of myopia on academic achievement or determined the direction of any cause and effect

\section{What this study adds}

By intention to treat analysis, children randomized to receive glasses over a school year had statistically significantly higher scores on a mathematics test than control children, though the observed disparity was smaller than the prespecified difference that the study was powered to detect

These effects were seen despite the fact that many children randomized to receive glasses did not wear them, and spectacle wear increased even among control children as a result of our study activities

Effect size increased with increasing blackboard use during teaching. This is biologically plausible owing to greater demands on distance vision in myopic children, and of practical importance in areas such as rural China where blackboards are widely used because of lack of money for textbooks

13 Congdon N, Zheng MW, Sharma A, Choi K, Song Y, Zhang MZ, et al. Prevalence and determinants of spectacle nonwear among rural Chinese secondary schoolchildren: the Xichang Pediatric Refractive Error Study report 3. Arch Ophthalmol 2008:126:1717-23.

14 Morgan IG, Ohno-Matsui K, Saw SM. Myopia. Lancet 2012;379:1739-48.

15 Sharma A, Congdon N, Patel M, Gilbert C. School-based approaches to correction of refractive error in children. Surv Ophthalmol 2012;57:272-83.

16 Mathers M, Keyes M, Wright M. A review of the evidence on the effectiveness of children's vision screening. Child Care Health Dev 2010;36:756-80.

17 Baidu Encyclopedi. Article on Tianshui. 2013. http://baike.baidu.com/view/14548.htm. [In Chinese.]

18 Wikipedia list of Chinese administrative divisions by GDP per capita in 2012. http://en wikipedia.org/wiki/List_of_Chinese_administrative_divisions_by_GDP_per_capita.

19 Baidu Encyclopedia. Article on Yulin. 2013. http://baike.baidu.com/view/52250.htm. [In Chinese.]

20 Congdon N, Patel N, Esteso P, Chikwembani F, Webber F, Msithini R, et al. The association between refractive cutoffs for spectacle provision and visual improvement among school-aged children in South Africa. Br J Ophthalmol 2008;92:13-8.

$21 \mathrm{Li}$ L, Lam J, Lu Y, Ye Y, Lam DS, Gao Y, et al. Attitudes of students, parents, and teachers towards glasses use in rural China. Arch Ophthalmol 2010;128:759-65.

22 Ferris FL 3rd, Kassoff A, Bresnick GH, Bailey I. New visual acuity charts for clinical research. Am J Ophthalmol 1982;94:91-6.

23 Congdon N, Li L, Zhang M, Yang A, Gao Y, Griffiths S, et al. Randomized, controlled trial of an educational intervention to promote spectacle use in rural China: the See Well to Learn Well Study. Ophthalmology 2011;118:2343-50.

24 Optimal Design Software for Multi-level and Longitudinal Research (Version 3.01). 2011. www.wtgrantfoundation.org

25 Zou G. A modified Poisson regression approach to prospective studies with binary data. Am J Epidemiol 2004;159:702-6.
26 Royston P. Multiple imputation of missing values. Stata J 2004:227-41.

27 Hill CJ, Bloom HS, Black R, Lipsey MW. Empirical benchmarks for interpreting effect sizes in research. MDRC working papers on research methodology. 2014. www.mdrc.org/ publications/459/full.pdf.

28 Zhang MZ, Lv H, Gao Y, Griffiths S, Sharma A, Lam DSC, et al. Visual morbidity due to inaccurate spectacles among school-children in rural China: the See Well to Learn Well Project, Report \#1. Invest Ophthalmol Vis Sci 2009;50:2011-7.

29 Dirani M, Zhang X, Goh LK, Young TL, Lee P, Saw SM. The role of vision in academic school performance. Ophthalmic Epidemiol 2010;17:18-24.

30 Survey in China shows a wide gap in income. 2014. www.nytimes.com/2013/07/20/world/ asia/survey-in-china-shows-wide-income-gap.html.

31 Liang X, Guo H, Jin C, Peng X, Zhang X. The effect of New Cooperative Medical Scheme on health outcomes and alleviating catastrophic health expenditure in China: a systematic review. PLoS One 2012;7:e40850.

$32 \mathrm{Li}$ L, Lam J, Lu Y, Ye Y, Lam DS, Gao Y, et al. Attitudes of students, parents, and teachers towards glasses use in rural China. Arch Ophthalmol 2010;128:759-65.

Accepted: 6 September 2014

\section{Cite this as: BMJ 2014;349:95740}

This is an Open Access article distributed in accordance with the Creative Commons Attribution Non Commercial (CC BY-NC 3.0) license, which permits others to distribute, remix, adapt, build upon this work non-commercially, and license their derivative works on different terms, provided the original work is properly cited and the use is non-commercial. See: http://creativecommons.org/licenses/by-nc/3.0/. 


\section{Tables}

Table 1| Baseline characteristics of 3177 children with correctable refractive error by group assignment. Values are numbers (percentages) unless stated otherwise

\begin{tabular}{|c|c|c|c|}
\hline Characteristics & Control group $(n=1036)$ & Voucher group $(n=988)$ & Free glasses group ( $n=1153)$ \\
\hline \multicolumn{4}{|l|}{ Individual level } \\
\hline Mean (SD) age (years) & $10.5(1.1)$ & $10.5(1.1)$ & $10.5(1.1)$ \\
\hline Male sex & $517(49.9)$ & $474(48.0)$ & $563(48.8)$ \\
\hline Wearing glasses at baseline* & $144(13.9)$ & $138(14.0)$ & $181(15.7)$ \\
\hline Gansu residence & $397(38.3)$ & $356(36.0)$ & $405(35.1)$ \\
\hline \multicolumn{4}{|l|}{ Mean (SD) refractive error (diopters): } \\
\hline$\leq-2$ & $410(39.6)$ & $374(37.9)$ & $431(37.4)$ \\
\hline$\geq-2$ to -0.5 & $561(54.2)$ & $548(55.5)$ & $665(57.7)$ \\
\hline$\leq-0.5$ to 0.5 & $18(1.7)$ & $17(1.7)$ & $10(0.9)$ \\
\hline$\geq 0.5$ & $47(4.5)$ & $49(5.0)$ & $47(4.1)$ \\
\hline Mean (SD) uncorrected visual acuity $<6 / 18$ in eye with better vision & $602(58.1)$ & $525(53.1)$ & $686(59.5)$ \\
\hline Mean (SD) baseline standardized mathematics score & $0.23(1.01)$ & $0.14(0.98)$ & $0.28(0.98)$ \\
\hline One or both parents with $\geq 12$ years of education $\dagger$ & $211(20.4)$ & $175(17.8)$ & $262(22.8)$ \\
\hline \multicolumn{4}{|l|}{ Family wealthł: } \\
\hline Bottom third & $333(32.2)$ & $351(35.6)$ & $368(31.9)$ \\
\hline Middle third & $373(36.1)$ & $328(33.2)$ & $355(30.8)$ \\
\hline Top third & $328(31.7)$ & $308(31.2)$ & $430(37.3)$ \\
\hline Boarding at school & $235(22.7)$ & $183(18.5)$ & $286(24.8)$ \\
\hline Both parents out-migrated for work§ & $115(11.1)$ & $103(10.4)$ & $109(9.5)$ \\
\hline \multicolumn{4}{|l|}{ Blackboard use in class: } \\
\hline Little or none & $277(26.7)$ & $260(26.3)$ & $456(39.6)$ \\
\hline Half of time & $439(42.4)$ & $398(40.3)$ & $362(31.4)$ \\
\hline Most or all of time & $320(30.9)$ & $330(33.4)$ & $335(29.1)$ \\
\hline \multicolumn{4}{|l|}{ Cluster level } \\
\hline \multicolumn{4}{|l|}{ Grade level (mean No/cluster (SD)): } \\
\hline Fourth grade & $5.0(3.4)$ & $4.6(3.7)$ & $5.5(4.8)$ \\
\hline Fifth grade & $7.3(4.5)$ & $7.3(4.8)$ & $8.3(5.3)$ \\
\hline $\begin{array}{l}\text { Uncorrected visual acuity }<6 / 18 \text {, in eye with better vision (mean No/cluster } \\
\text { (SD)) }\end{array}$ & $7.2(4.7)$ & $6.3(5.0)$ & $8.2(6.1)$ \\
\hline
\end{tabular}

${ }^{*}$ Defined as having glasses at school at baseline, having previously been told to bring them to school.

†Data missing for seven students.

$\ddagger$ Data missing for three students.

$\S$ Data missing for eight students. 
Table 2| Baseline characteristics of children with correctable refractive error allocated in trial, by group assignment with regard to the educational intervention. Values are numbers (percentages) unless stated otherwise

\begin{tabular}{|c|c|c|}
\hline Characteristics & Education on importance of glasses ( $n=1648)$ & No education $(n=1529)$ \\
\hline \multicolumn{3}{|l|}{ Individual level } \\
\hline Mean (SD) age (years) & $10.5(1.1)$ & $10.5(1.1)$ \\
\hline Male sex & $794(48.2)$ & $760(49.7)$ \\
\hline Gansu residence & $624(37.9)$ & $534(34.9)$ \\
\hline Wearing glasses at baseline ${ }^{*}$ & $221(13.4)$ & $242(15.8)$ \\
\hline Aware of having refractive error at baseline & $744(45.1)$ & $731(47.8)$ \\
\hline Believes wearing glasses harms vision & $686(41.6)$ & $591(38.7)$ \\
\hline \multicolumn{3}{|l|}{ Refractive error (diopters): } \\
\hline$\leq-2$ & $630(38.2)$ & $585(38.3)$ \\
\hline$\geq-2$ to -0.5 & $915(55.5)$ & $859(56.2)$ \\
\hline$\geq-0.5$ to 0.5 & $27(1.6)$ & $18(1.2)$ \\
\hline$\geq 0.5$ & $76(4.6)$ & $67(4.4)$ \\
\hline Uncorrected visual acuity $<6 / 18$, in eye with better vision & $936(56.8)$ & $877(57.4)$ \\
\hline One or both parents with $\geq 12$ years of education $\dagger$ & $338(20.6)$ & $311(20.4)$ \\
\hline \multicolumn{3}{|l|}{ Family wealth $\ddagger$ : } \\
\hline Bottom third & $555(33.7)$ & $497(32.5)$ \\
\hline Middle third & $560(34.0)$ & $496(32.5)$ \\
\hline Top third & $532(32.3)$ & $534(35.0)$ \\
\hline Boarding at school & $379(23.0)$ & $325(21.3)$ \\
\hline Both parents out-migrated for work§ & $172(10.5)$ & $155(10.1)$ \\
\hline \multicolumn{3}{|l|}{ Cluster level } \\
\hline \multicolumn{3}{|l|}{ Grade level (mean No/cluster (SD)): } \\
\hline Fourth grade & $5.3(4.1)$ & $4.8(3.9)$ \\
\hline Fifth grade & $7.8(4.9)$ & $7.5(4.9)$ \\
\hline $\begin{array}{l}\text { Uncorrected visual acuity }<6 / 18 \text {, in eye with better vision (mean No/cluster } \\
\text { (SD)) }\end{array}$ & $7.4(5.5)$ & $7.0(5.2)$ \\
\hline
\end{tabular}
(SD))

*Defined as having glasses at school at baseline, having previously been told to bring them to school. †Data missing for seven students.

fData missing for three students.

$\S$ Data missing for eight students. 
Table 3| Effect of treatment arms on endline standardized mathematics score, controlling for baseline score

\begin{tabular}{lccccc} 
& & \multicolumn{2}{c}{ Mean (SD) score } & & Adjusted* difference (95\% Cl) in endline score $v$ \\
Intervention groups & No & Baseline & Endline & Unadjusted change in score (95\% Cl) & (reference) \\
\cline { 3 - 4 } Total & 3177 & $0.22(0.99)$ & $0.34(0.99)$ & $0.13(0.08$ to 0.17$)$ & $0.04(-0.05$ to 0.14$)$ \\
\hline Control & 1036 & $0.23(1.01)$ & $0.29(1.00)$ & $0.07(-0.0002$ to 0.14$)$ & $0.11(0.01$ to 0.21$)$ \\
\hline Voucher & 988 & $0.14(0.98)$ & $0.29(0.98)$ & $0.15(0.08$ to 0.21$)$ & (reference) \\
\hline Free glasses & 1153 & $0.28(0.98)$ & $0.43(0.97)$ & $0.16(0.07$ to 0.24$)$ & $-0.01(-0.09$ to 0.07$)$ \\
\hline No education & 1529 & $0.15(1.00)$ & $0.31(1.01)$ & $0.16(0.10$ to 0.22$)$ & (reference) \\
\hline Education & 1648 & $0.27(0.97)$ & $0.37(0.96)$ & $0.10(0.04$ to 0.16$)$ & $0.03(-0.12$ to 0.17$)$ \\
\hline Control: no education & 510 & $0.21(1.04)$ & $0.27(1.05)$ & $0.06(-0.04$ to 0.16$)$ & $0.10(-0.03$ to 0.23$)$ \\
\hline Control: education & 526 & $0.24(0.98)$ & $0.32(0.95)$ & $0.08(-0.02$ to 0.17$)$ & $0.02(-0.12$ to 0.16$)$ \\
\hline Voucher: no education & 492 & $0.08(0.97)$ & $0.29(0.97)$ & $0.21(0.12$ to 0.30$)$ & $0.12(-0.03$ to 0.27$)$ \\
\hline Voucher: education & 496 & $0.19(0.98)$ & $0.28(1.00)$ & $0.09(-0.01$ to 0.19$)$ & $0.13(-0.01$ to 0.27$)$ \\
\hline Free glasses: no education & 527 & $0.17(0.99)$ & $0.37(1.00)$ & $0.19(0.07$ to 0.32$)$ &
\end{tabular}

Linear regression using endline math score as dependent variable.

*Adjusted for baseline score. 
Table 4| Linear regression model of potential predictors of endline math score

Model adjusted for baseline math score $(n=3177)$

\section{Characteristics}

Baseline standardized mathematics score (SD)

Intervention group (control group as reference)

\begin{tabular}{|c|c|c|c|c|}
\hline Voucher & $0.04(-0.05$ to 0.14$)$ & 0.35 & $0.04(-0.05$ to 0.13$)$ & 0.42 \\
\hline Free glasses & $0.11(0.01$ to 0.21$)$ & 0.03 & $0.10(0.002$ to 0.19$)$ & 0.04 \\
\hline Age (years) & $-0.14(-0.17$ to -0.11$)$ & $<0.001$ & $-0.14(-0.17$ to -0.11$)$ & $<0.001$ \\
\hline Male sex & $-0.02(-0.07$ to 0.04$)$ & 0.58 & - & - \\
\hline Wearing glasses at baseline & $0.05(-0.03$ to 0.12$)$ & 0.25 & - & - \\
\hline Gansu residence & $-0.17(-0.25$ to -0.08$)$ & $<0.001$ & $-0.13(-0.22$ to -0.04$)$ & 0.003 \\
\hline \multicolumn{5}{|l|}{$\begin{array}{l}\text { Refractive error ( } \geq-0.5 \mathrm{D} \text { to } 0.5 \mathrm{D} \text { as } \\
\text { reference): }\end{array}$} \\
\hline$\leq-2 \mathrm{D}$ & $0.14(-0.16$ to 0.43$)$ & 0.37 & 一 & 一 \\
\hline$-2 \mathrm{D}$ to $-0.5 \mathrm{D}$ & $0.10(-0.21$ to 0.40$)$ & 0.54 & - & - \\
\hline$\geq 0.5 \mathrm{D}$ & $0.12(-0.19$ to 0.43$)$ & 0.45 & - & - \\
\hline $\begin{array}{l}\text { One or both parents with } \geq 12 \text { years } \\
\text { of education } \neq\end{array}$ & 0.07 (0.008 to 0.13$)$ & 0.03 & $0.03(-0.04$ to 0.09$)$ & 0.40 \\
\hline \multicolumn{5}{|l|}{$\begin{array}{l}\text { Family wealth (poorest third as } \\
\text { reference)§: }\end{array}$} \\
\hline Middle third & $0.06(-0.01$ to 0.13$)$ & 0.11 & $0.03(-0.04$ to 0.10$)$ & 0.38 \\
\hline Top third & $0.07(0.001$ to 0.14$)$ & 0.05 & $0.01(-0.06$ to 0.08$)$ & 0.83 \\
\hline Boarding at school & $0.05(-0.03$ to 0.14$)$ & 0.20 & $0.03(-0.05$ to 0.11$)$ & 0.49 \\
\hline Both parents out-migrated for work & $0.02(-0.07$ to 0.11$)$ & 0.68 & - & - \\
\hline
\end{tabular}

\section{$\mathrm{D}=$ diopter.}

*Except for regression coefficient for baseline math score (simple regression), coefficients for different variables are for multiple models with endline math score as dependent variable, adjusted for baseline math score.

†Including variables associated with endline math score $\mathrm{P}<0.20$ in model also including baseline math score.

‡Data missing for seven students.

§Data missing for three students.

IData missing for eight students. 
Table 5| Effect of treatment arms on directly observed (primary outcome) and self reported (secondary outcome) glasses use at endline. Values are numbers (percentages) unless stated otherwise

\begin{tabular}{|c|c|c|c|c|c|c|c|c|}
\hline \multirow[b]{2}{*}{$\begin{array}{l}\text { Intervention } \\
\text { groups }\end{array}$} & \multirow[b]{2}{*}{ No } & \multirow[b]{2}{*}{$\begin{array}{l}\text { Wearing } \\
\text { glasses at } \\
\text { baseline }^{\star}\end{array}$} & \multicolumn{3}{|c|}{ Observation of wear† } & \multicolumn{3}{|c|}{ Self reported wear $\ddagger$} \\
\hline & & & Wearing & $\begin{array}{c}\text { Relative risk } \\
(95 \% \mathrm{Cl}) \S\end{array}$ & $\begin{array}{c}\text { Relative risk } \\
(95 \% \mathrm{CI}) \text {, full } \\
\text { model }\end{array}$ & Wearing & $\begin{array}{c}\text { Relative risk } \\
(95 \% \mathrm{CI}) \S\end{array}$ & $\begin{array}{c}\text { Relative risk } \\
(95 \% \mathrm{Cl}) \text {, full } \\
\text { model }^{\star \star}\end{array}$ \\
\hline Total & 3177 & $463(15)$ & $1096(34)$ & & & $1803(57)$ & & \\
\hline Control & 1036 & $144(14)$ & $266(26)$ & 1 (reference) & 1 (reference) & $386(37)$ & 1 (reference) & 1 (reference) \\
\hline Voucher & 988 & $138(14)$ & $361(37)$ & $\begin{array}{c}1.42(1.16 \text { to } \\
1.73)\end{array}$ & 1.44 (1.19 to 1.76$)$ & $627(63)$ & $\begin{array}{c}1.70(1.49 \text { to } \\
1.94)\end{array}$ & $1.72(1.51$ to 1.96$)$ \\
\hline Free glasses & 1153 & $181(16)$ & $469(41)$ & $\begin{array}{c}1.54(1.28 \text { to } \\
1.85)\end{array}$ & 1.55 (1.30 to 1.85$)$ & $790(68)$ & $\begin{array}{c}1.81(1.60 \text { to } \\
2.05)\end{array}$ & 1.81 (1.61 to 2.04$)$ \\
\hline No education & 1529 & $242(16)$ & $508(33)$ & 1 (reference) & 1 (reference) & $818(53)$ & 1 (reference) & 1 (reference) \\
\hline Education & 1648 & $221(13)$ & $588(36)$ & $\begin{array}{c}1.11(0.95 \text { to } \\
1.31)\end{array}$ & $1.11(0.94$ to 1.30$)$ & $986(60)$ & $\begin{array}{c}1.14(1.03 \text { to } \\
1.26)\end{array}$ & $1.13(1.02$ to 1.25$)$ \\
\hline $\begin{array}{l}\text { Control: no } \\
\text { education }\end{array}$ & 510 & $85(17)$ & $129(25)$ & 1 (reference) & 1 (reference) & $178(35)$ & 1 (reference) & 1 (reference) \\
\hline $\begin{array}{l}\text { Control: } \\
\text { education }\end{array}$ & 526 & $59(11)$ & $137(26)$ & $\begin{array}{c}1.11(0.84 \text { to } \\
1.47)\end{array}$ & 1.08 (0.82 to 1.42$)$ & $209(40)$ & $\begin{array}{c}1.18(0.94 \text { to } \\
1.49)\end{array}$ & $1.17(0.94$ to 1.46$)$ \\
\hline $\begin{array}{l}\text { Voucher: no } \\
\text { education }\end{array}$ & 492 & $76(15)$ & $185(38)$ & $\begin{array}{c}1.51(1.17 \text { to } \\
1.95)\end{array}$ & 1.51 (1.16 to 1.96$)$ & $301(61)$ & $\begin{array}{c}1.77(1.47 \text { to } \\
2.14)\end{array}$ & 1.78 (1.48 to 2.14$)$ \\
\hline $\begin{array}{l}\text { Voucher: } \\
\text { education }\end{array}$ & 496 & $62(13)$ & $176(35)$ & $\begin{array}{c}1.48(1.08 \text { to } \\
2.03)\end{array}$ & 1.50 (1.10 to 2.03$)$ & $326(66)$ & $\begin{array}{c}1.94(1.60 \text { to } \\
2.36)\end{array}$ & 1.95 (1.62 to 2.36$)$ \\
\hline $\begin{array}{l}\text { Free glasses: no } \\
\text { education }\end{array}$ & 527 & $81(15)$ & $194(37)$ & $\begin{array}{c}1.48(1.13 \text { to } \\
1.92)\end{array}$ & $1.46(1.13$ to 1.89$)$ & $339(64)$ & $\begin{array}{c}1.86(1.55 \text { to } \\
2.23)\end{array}$ & 1.86 (1.56 to 2.21$)$ \\
\hline $\begin{array}{l}\text { Free glasses: } \\
\text { education }\end{array}$ & 626 & $100(16)$ & $275(44)$ & $\begin{array}{c}1.75 \text { ( } 1.35 \text { to } \\
2.27)\end{array}$ & 1.74 (1.35 to 2.23$)$ & $451(72)$ & $\begin{array}{c}2.08(1.74 \text { to } \\
2.48)\end{array}$ & 2.06 (1.73 to 2.44$)$ \\
\hline
\end{tabular}

*Defined as having glasses to hand at baseline, having previously been told to bring them to school.

†Defined as wearing glasses during an unannounced examination.

$\ddagger$ Defined as self report of "wearing glasses for study" or "always wearing glasses."

$\S$ Adjusted for baseline wear.

IIncluding variables associated with observed wear $(\mathrm{P}<0.20)$ in model including baseline wear (data not shown): age (years), aware of having refractive error at baseline, refractive error, visual acuity $<6 / 18$ (eye with better vision).

${ }^{* *}$ Including variables associated with self reported wear $(P<0.20)$ in model including baseline wear (data not shown): aware of having refractive error at baseline refractive error, visual acuity $<6 / 18$ (eye with better vision), baseline standardized math score. 


\section{Figure}

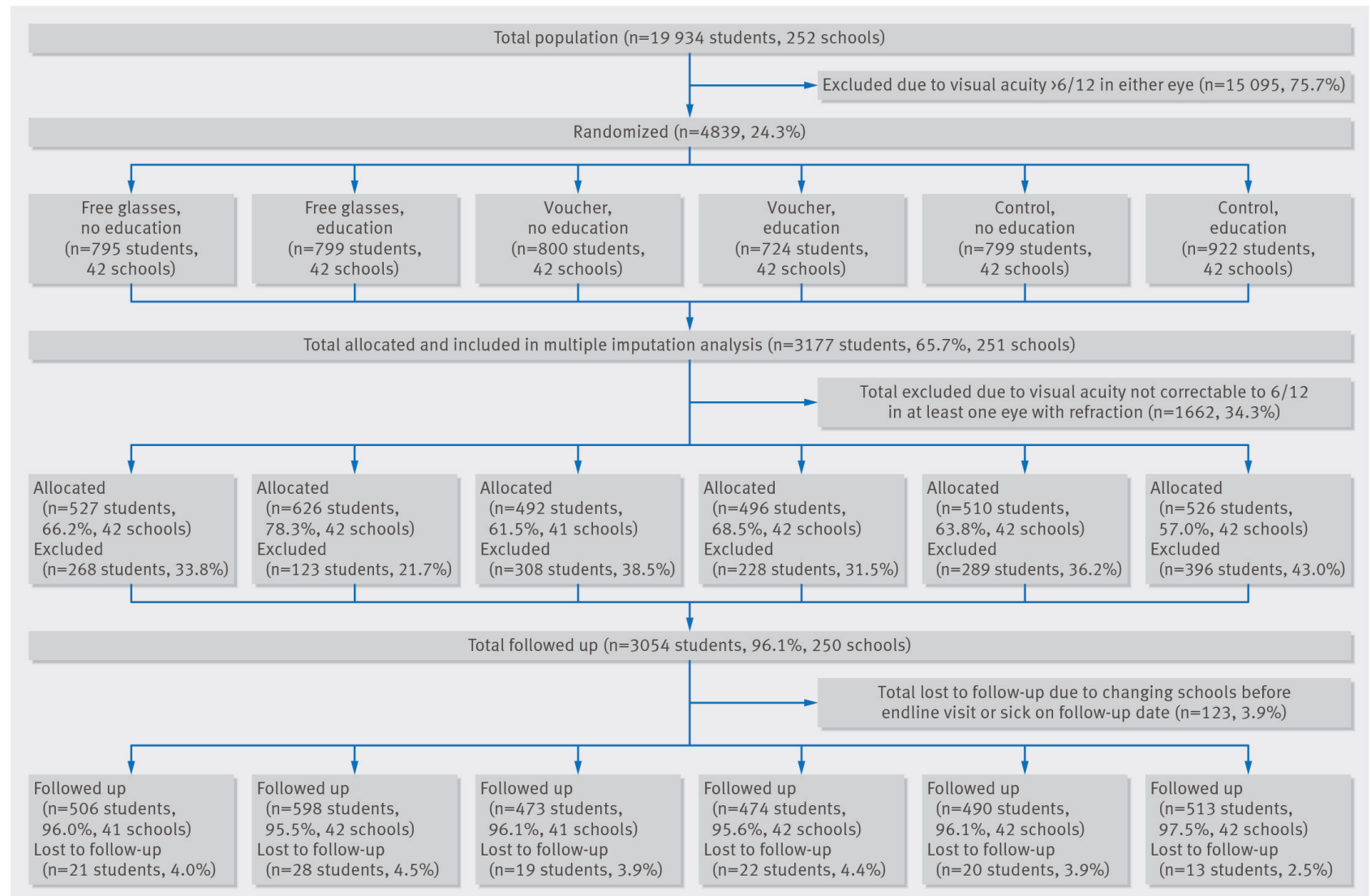

Enrolment and progress of children through study 